\title{
Delta Sistemlerinde Peyzaj Deseni ve Mekansal Bağlantılılığın Analizi, Büyük Menderes Deltası Örneği
}

\author{
Ebru ERSOY TONYALOĞLU ${ }^{* 1}$ (D), Birsen KESGIN ATAK ${ }^{1}$ \\ ${ }^{1}$ Aydın Adnan Menderes Üniversitesi, Ziraat Fakültesi, Peyzaj Mimarlığı Bölümü, Güney Kampüs, 09100 Aydın, \\ Türkiye
}

Öz: Bu çalışmanın amacı Büyük Menderes Deltası Milli Parkı, Bafa Gölü Tabiat Parkı ve yakın çevresinde yer alan delta sistemindeki habitatların tanımlanması, peyzaj desenin analiz edilmesi ve mekansal bağlantıııık bakımından doğrusal habitatların tüm delta sisteminin mekansal bağlantılıı̆̆ına katkılarının değerlendirilmesidir. Çalışmada, araştırma alanının mekansal özelliklerinin analizini gerçekleştirmek amacıyla kullanılan habitat haritası, 11 Ağustos 2017 tarihli Sentinel-2A uydu görüntüsü ile yardımcı veriler kullanılarak, nesne tabanlı sınıflandırma yöntemi ile elde edilmiştir. Peyzaj deseninin değerlendirilmesi ve mekansal bağlantılıı̆ıı ölçülmesinde yedi temel peyzaj metriği hesaplanmıştır. Çalışma alanında hakim habitat tipini Tarla ve Bahçe Tarımı oluşturmaktadır. Akarsular ve Durgun Tatı Sular mekansal bağlantılığı en yüksek olan habitat tipleri iken, bunu Doğu Quercus Coccifera Garigleri, Sarcopoterium spinosum Friganaları ve Arbutus andrachne Garigleri izlemektedir. Bununla birlikte çalışma sonucunda, delta sistemlerinde akarsu koridorları ve tarla sınıları ile yol kenarlarında bulunan vejetasyon koridorlarının, diğer doğal ve yarı doğal habitatların mekansal bağlantıılı̆ıını artıırma potansiyeline sahip olduğu tespit edilmiştir.

Anahtar Kelimeler: Peyzaj metrikleri, Sentinel-2A, nesne tabanlı sınıflandırma, doğrusal habitatlar

\section{Analysis of Landscape Structure and Spatial Connectivity in Delta Systems, The Case of Big Meander Delta}

\begin{abstract}
The aim of this study is to define the habitats and analyse the landscape pattern of natural and semi-natural habitats in the delta system, that are located in Big Meander Delta National Park, Bafa Lake Natural Park and its vicinity as well as determining the contribution of linear habitats into the spatial connectivity of the whole delta system. In this study, the habitat map used for the spatial analysis of the research area was based on an object-based classification method using the Sentinel-2A satellite image (dated August 11, 2017) together with auxiliary data. Seven landscape metrics were calculated to evaluate the landscape pattern. The dominant habitat type in the study area is composed of Arable Land and Horticulture. Whilst Rivers and Standing Fresh Water have the strongest spatial connectivity, it is followed by Eastern Quercus Coccifera Garrigues, Sarcopoterium spinosum Friganas and Arbutus andrachne Garrigues. As a result the study, it was also found that river corridors and vegetation corridors along the roadsides and the borders of agricultural areas have a potential to strengthen the spatial connectivity of other natural and semi-natural habitats in delta systems.
\end{abstract}

Keywords: Landscape metrics, Sentinel-2A, object-based classification, linear habitats

\section{GíRiş}

Zengin hayvan ve bitki çeşitliliği içeren delta sistemleri, su kalitesinin yükseltilmesi, sel ile kuraklık riskinin azaltılması ve iklim değişikliğinin olumsuz etkilerinin azaltılması gibi işlevleri yerine getirmektedir. Ekonomik ve kültürel bakımdan da yaşam ortamı olarak tercih edilen delta sistemleri, toplumların sosyo-ekonomik gelişimlerinde önemli bir rol oynamaktadır (Thompson, 2002; Atalay, 2008). Ancak, yoğun nüfus artışına maruz kalan bu alanlarda hızlı ve düzensiz yapılaşma gibi faaliyetler peyzaj desenini değiştirmekte ve delta sistemlerinin gün geçtikçe bozulmasına yol açmaktadır (Anonim, 2008). Ülkemizde su rejimine yapılan müdahaleler, su kalitesinin bozulması, habitat tahribi, doğal sulak alanlara yabancı türlerinin atılması ile delta sistem bütününün yönetimi ile ilişkili birçok sorun yaşanmaktadır. Ayrıca, delta sistemleri genel olarak sahip oldukları verimli topraklar nedeniyle yoğun tarımsal aktivitelere maruz kalmaktadır. Tarım alanlarındaki artış ise, doğal ve yarı doğal habitatlarda kayıplar, otlak alanlarında kayıplar, aşırı gübre ve pestisit kullanımı ve birçok hayvan türünün doğal yaşam alanlarının tahrip edilmesi / parçalanması gibi sorunlara neden olmaktadır (Benton ve ark., 2003; Lacoeuilhe ve ark., 2018). Bu sorunların ortadan kaldırılması için delta sistemlerinin bütüncül bir anlayış ile yönetilmesi gerekmektedir. Bunun sağlanabilmesi için öncelikle bu sistemleri oluşturan doğal ve yarı doğal habitatların tanımlanması ve her bir habitatın kendine özgü karakteristikleri ile bütüncül bir sistem olarak mekansal özelliklerinin belirlenmesi gerekmektedir (Forman, 1995).

Bu çalışmada seçilen örnek delta sistemi iki farklı koruma statüsüne sahip olan Büyük Menderes Deltası Milli Parkı ve Bafa Gölü Tabiat Parkı arasında yer alan Büyük Menderes

Sorumlu Yazar: ebru.ersoy@adu.edu.tr Bu çalışma Aydın Adnan Menderes Üniversitesi Bilimsel Araştırma Projeleri Koordinasyon Birimi Tarafından Desteklenmiştir. Proje No: ZRF-17044.

Geliş Tarihi: 5 Temmuz 2019

Kabul Tarihi: 20 Kasım 2019 
delta ovasını içermektedir. Delta ovasının çoğunluğunu alüviyal topraklar oluşturmakta ve bu ova ülkemizin en önemli tarım alanlarından birisini oluşturmaktadır. Çalışma alanının batı bölümüne doğru yükseklik azalmakta, tuzlu ve alkali özellikte olan toprakların hakim olduğu alanlarda ise Büyük Menderes delta ovasının bazı bölümleri deniz seviyesine kadar inmekte ve tuzlu bataklık / tuzcul çalılık alanlara dönüşmektedir (Sütgibi, 2008). Büyük Menderes delta ovasında yer alan doğal tarla sınırları ile sulama kanalları ve yol kenarlarında yer alan doğal vejetasyon öğeleri, bu alanda mekansal ve ekolojik bağlantılılığa destek olan en önemli peyzaj öğeleri arasında yer almaktadır. Eşbah ve ark. (2009) bu alanda yürüttükleri bir araştırma projesinde, alanda 4 tip koridor olduğunu, bunlardan birisinin sulama kanallarından (yapay koridor), diğer üçünün ise doğrusal vejetasyon koridorları ile akarsu koridorları ve tarla sınırlarında yer alan vejetasyon koridorlarından (doğal koridorlar) oluştuğunu bulmuştur. Yapay ve doğal öğelerden oluşan bu koridorlar, diğer doğal alanları birbirine bağlayarak çeşitli hayvan türlerine peyzaj içinde hareket etme olanağı sağlamakta, ve yaşam ortamı oluşturma, barınma, beslenme, üreme, saklanma gibi peyzajın sağladığı diğer fonksiyonlara da önemli katkılar sağlayarak alanın doğal değerini yükseltmektedirler (Redman ve ark., 2008). Bu bakımdan, özellikle çalışma alanının doğu ve batı yönünde farklı büyüklük ve mekansal özellikler ile yayılış gösteren doğal ve yarı doğal habitatların birbirleri ile fiziksel bağlantılılığının sağlanmasında, doğrusal koridorların katkısının belirlenmesi büyük önem taşımaktadır.

Bu çalışma ile Dilek Yarımadası-Büyük Menderes Deltası Milli Parkı, Bafa Gölü Tabiat Parkı, Azap Gölü, Sarıkemer taşkını, Avşar Gölü (taşkını) ve Büyük Menderes Nehrinin oluşturduğu delta sisteminde yer alan habitatların haritalanması, tanımlanması ve peyzaj deseninin analiz edilmesinin yanı sıra mekansal bağlantılılık bakımından doğrusal habitatların tüm delta sisteminin mekansal bağlantılılığına katkılarının değerlendirilmesi amaçlanmıştır. $\mathrm{Bu}$ amaçla birçok çalışmada geniş alanlarda mekansal peyzaj özelliklerinin sayısal olarak ifade ve analiz edilmesine olanak sağlayan peyzaj metrikleri kullanılmıştır (Eşbah, 2010; Aguilera ve ark., 2011). Peyzaj metrikleri, peyzaj deseni hakkında niceliksel veri sağlarken aynı zamanda ilgili peyzajın işleyişi hakkında da aydınlatıcı bilgiler sunmaktadır. Bir peyzajın mekansal özelliklerinin sayısal olarak nitelenmesine yardımcı olan peyzaj metrikleri, daha objektif planlama ve yönetim kararlarının/önerilerinin elde edilmesine de yardımcı olmaktadır. Bu çalışmanın amacı doğrultusunda örnek çalışma alanında belirlenen habitat tiplerine ilişkin peyzaj deseni analizlerine dayanarak, şu sorulara yanıt aranmaktadır: (1) mekansal özellikleri göz 210 önüne alındığında, alanda hakim ve mekansal bağlantılılığı en güçlü olan habitat tipleri nelerdir? (2) doğrusal habitatların tüm delta sisteminde yer alan diğer doğal ve yarı doğal habitatların mekansal bağlantılılığına katkıları nedir?

\section{MATERYAL VE YÖNTEM}

\section{Materyal}

Çalışma alanı, Dilek Yarımadası-Büyük Menderes Deltası Milli Parkı, Bafa Gölü Tabiat Parkı, Azap Gölü ve taşkın alanı, Sarıkemer taşkın alanı ile Büyük Menderes Nehri'nin oluşturduğu toplam 55165 ha alana sahip olan delta sisteminden oluşmaktadır (Şekil 1).

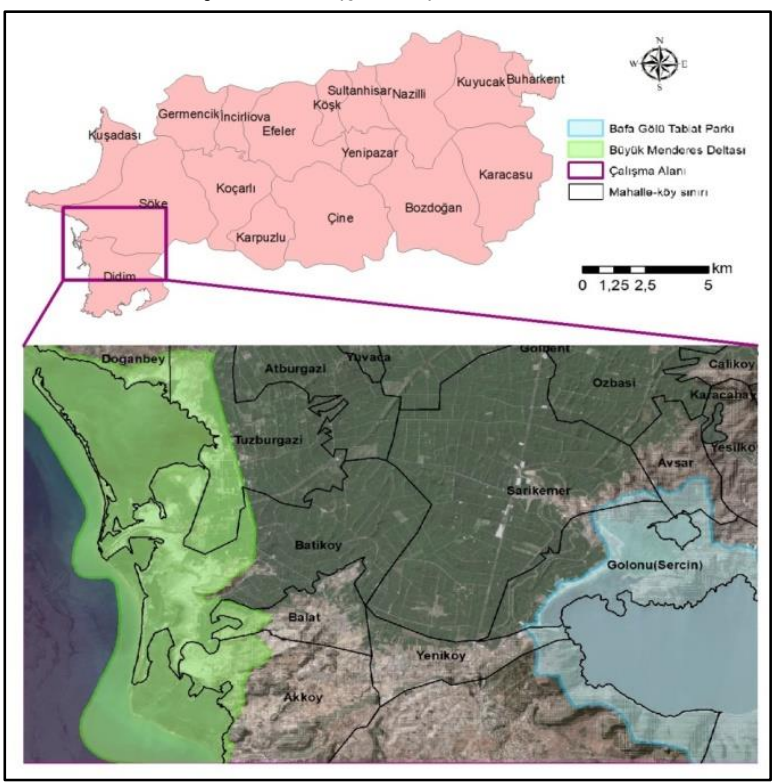

Şekil 1. Çalışma alanı

Yaklaşık 27675 ha alan kaplayan Dilek Yarımadası-Büyük Menderes Deltası Milli Parkı'nın 10985 ha'ını Dilek Yarımadası, 16690ha'nı ise 1966 yılında Milli Park ilan edilen Büyük Menderes Deltası oluşturmaktadır. Uluslararası öneme sahip 'A Sınıfı Sulak Alan' özelliği taşımakta olan Büyük Menderes Deltası'nın denize döküldüğü ağız kısmında birçok lagün ve bataklık bulunmaktadır (Anonim, 2017). Dilek Yarımadası ise biyolojik çeşitliliği ile Avrupa Konseyi tarafından 'Flora Biyogenetik Rezerv Alanı' olarak kabul edilmiştir (Bilgili, 2002). Çalışma alanında yer alan diğer koruma statüsü olan alan ise Bafa Gölü Tabiat Parkı'dır. Geçmişte bir taşkın ovası özelliği taşıyan Bafa Gölü ve yakın çevresi, günümüzde Büyük Menderes Deltasının sahip olduğu ekosistem özelliklerini taşımaktadır (Müllenhoff ve ark., 2004).

Çalışma materyali, $10 \mathrm{~m}$ yersel çözünürlüklü Sentinel-2A uydu görüntüsü, vektör formatta toprak haritası ve $30 \mathrm{~m}$ yersel çözünürlüklü Aster Global DEM (sayısal yükseklik modeli)'nden oluşmaktadır. Çalışma alanındaki delta sistemi 
içinde bulunan habitatların sınıflandırılmasında Sentinel-2A uydu görüntüsü temel veri olarak kullanılmıştır (ESA, 2018). Çalışmada Sentinel-2A uydu görüntüsünün B02 (mavi-490 $\mathrm{nm}$ ), B03 (yeşil-560 nm) ve B04 (kırmızı-665 nm) bantlarından oluşan gerçek renkli görüntüsü (true colour image) kullanılmıştır. Toprak haritası ve sayısal yükseklik modeli ise sınıflandırma doğruluğunun arttırılması amacıyla yardımcı veri olarak kullanılmıştır.

\section{Vejetasyon Analizi}

Çalışma alanında yer alan habitatların sınıflandırılması için öncelikle vejetasyon analizi yöntemi ile alanda mevcut bitki toplulukları tanımlanmıştır. Bunun için, 2017 yılında farklı tarihlerde 6 günlük arazi çalışması gerçekleştirilerek, bu arazi çalışmalarında kaydedilen bitki taksonlarının topluluk oluşturma açısından; bulunma, bolluk-örtülülük, frekans ve konstans değerleri gibi özellikleri belirlenmiştir. Vejetasyon analizi sonucunda elde edilen bulgular ışığında, çalışma alanında temel habitat tipleri saptanmıştır. Ayrıca, arazi çalışmaları sırasında bu habitatları temsil eden mekansal kontrol alanları da belirlenmiştir (Ersoy ve ark., 2019).

\section{Habitatların Sınıflandırılması}

Sentinel-2A uydu görüntüsünü sınıflandırmak ve çalışma alanında yer alan habitat tiplerini belirlemek amacıyla eCognition yazılımında yer alan nesne tabanlı sınıflandırma yöntemlerinden en yakın komşu (nearest neighbour) kontrollü yöntemi kullanılmıştır. Sınıflandırmada $10 \mathrm{~m}$ yersel çözünürlükte 7 farklı katmandan yararlanılmıştır. Bunlar; Sentinel-2A uydu görüntüsünün B02 (mavi), B03 (yeşil) ve B04 (kırmızı) bantları, sayısal yükseklik modeli, toprak haritasından elde edilen büyük toprak grubu, arazi kullanma kabiliyet sınıfı ve diğer toprak özelliklerine ait katmanlardan oluşmaktadır.

Çalışmada kullanılan nesne tabanlı kontrollü sınıflandırma yöntemi (a) segmentasyon aşaması, (b) örnek habitat tiplerinin ve örnek noktaların seçilmesi ve (c) en yakın komşu sınıflandırma yöntemi ile kontrollü sınıflandırma Çizelge 1. Araştırmada kullanılan peyzaj metrikleri

\begin{tabular}{lll}
\hline Metrik Adı/Birim & Kısaltma & Seçim Sebebi \\
\hline Toplam yama alanı, ha & CA & Baskınlık, hakimiyet \\
Peyzaj Yüzdesi, \% & PLAND & Baskınlık, hakimiyet \\
Parça/yama sayısı & NP & Parçalanma \\
Ortalama alan, ha & AREA_MN & NP ile birlikte parçalanma \\
Öklid en yakın komşu mesafesi, m & ENN_AM & Parçalanma ve izolasyon \\
Yakınlık indeksi & PROX_AM & Parçalanma/Bağlantılılık \\
Etkin ağ büyüklüğü, ha & MESH & Parçalanma/Bağlantılılık \\
\hline
\end{tabular}

\section{BULGULAR}

\section{Çalışma Alanında Belirlenen Habitat Tipleri}

Çalışma alanında toplam 17 adet habitat tipi tanımlanmıştır. Gerçekleştirilen doğruluk analizi sonucunda, elde edilen habitat haritasının toplam doğruluk oranının \%83.33 (kappa $=0.82$ ) olduğu bulunmuştur. Çalışma alanına ait sonuç habitat haritası Şekil 2'de verilmiştir.
ERSOY TONYALIOĞLU E, KESGIN ATAK B nesnelerin spektral ve yersel özelliklerinin benzerlik göstermesi nedeniyle karışıklığa sebep olan habitat sınıflarında elle düzeltme yapılarak, sonuç habitat haritasının doğruluğu arttırılmıştır. Ayrıca habitat parçalanmasında önemli etkisi olan yol ve kanallara ilişkin vektör veri elde edilen habitat haritası ile çakıştırılarak haritanın ve analiz sonuçlarının doğruluğunun arttırılması amaçlanmıştır. Son olarak, Sentinel uydu görüntüsü üzerinden tarla sınırlarında ve yol kenarlarında yer alan vejetasyon koridorlarının ortalama genişlikleri hesaplanarak; yol, kanal ve tarla sınırlarında dışa doğru $5 \mathrm{~m}$ zon oluşturulup, tarla sınırları ve yol kenarlarında yer alan vejetasyon sınıfı elde edilmiştir. Elde edilen habitat haritasının doğruluk analizi, ArcGIS 10.5.1 yazılımı yardımı ile örneklere dayalı hata matrisi yöntemi kullanılarak gerçekleştirilmiştir (Congalton ve Gren, 2008).

Peyzaj Metriklerinin Hesaplanması ile Peyzaj Deseninin ve Mekansal Bağlantılığın Değerlendirilmesi

Mekansal bağlantılılık analizleri için nesne tabanlı kontrollü sınıflandırma ile vektör tabanlı olarak hazırlanmış olan habitat haritası $5 \mathrm{~m}$ çözünürlüklü raster görüntüye dönüştürülerek 7 peyzaj metriği hesaplanmıştır (Çizelge 1).

Öncelikle çalışma alanında yer alan tüm habitatların mekansal özellikleri tanımlanarak değerlendirilmiştir. Daha sonra, alandaki tüm doğal ve yarı doğal habitatlar belirlenip tek bir sınıf altında birleştirilmiş ve $5 \mathrm{~m}$ çözünürlükte örneklenerek seçilen peyzaj metrikleri değerlendirilmiştir. Delta sisteminde yer alan doğrusal habitatların tüm delta sisteminin mekansal bağlantılılığına katkılarının değerlendirilebilmesi için, aynı işlem öncelikle en yüksek mekansal bağlantılılığa sahip olan akarsuların tüm doğal ve yarı doğal habitatlara eklenmesi ile tekrar edilmiş, son olarak ise tarla sınırları ile yol kenarlarında bulunan vejetasyon koridorları elde edilen haritaya eklenerek peyzaj metrikleri hesaplanmıştır. aşamalarından oluşmaktadır. Sınıflandırma sonucunda,

\section{Peyzaj Deseni Analiz Sonuçları}

FRAGSTATS yazılımında seçilen ve hesaplanan peyzaj metriklerine ilişkin sonuçlar Çizelge 2'de verilmiştir. Çalışma alanında hakim habitat tipi tarım alanlarından, Tarla ve Bahçe Tarımı́ndan (sırasıyla \%41.21 ve \%13.29) oluşmaktadır. Ortalama yama büyüklükleri 14.50 ha ve 5.49 


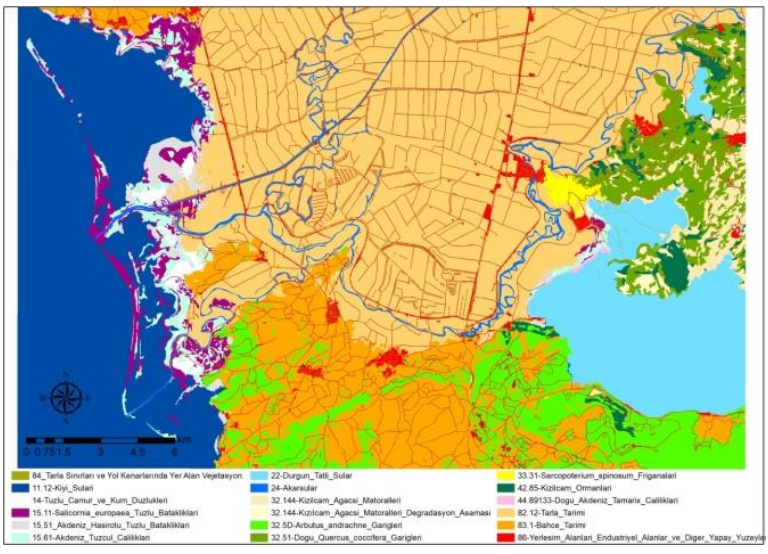

Şekil 2. Çalışma alanı habitat haritası

ha olan bu habitatlar, yüksek yama sayıları ile peyzajda parçalı bir yapı göstermektedirler. Diğer bir kültürel habitat sınıfını oluşturan Yerleşim Alanları, Endüstriyel Alanlar ve Diğer Yapay Yüzeyler ise toplam alanın yalnızca \%5.54'ünü kaplamaktadır. Beklenildiği üzere Yerleşim Alanları, Endüstriyel Alanlar ve Diğer Yapay Yüzeyler çalışma alanında daha parçalı ancak birbirine yakın yamalar halinde yer almaktadır.

Çalışma alanını doğal bir ağ şeklinde kaplamakta olan akarsu ile tarla sınırlarında ve yol kenarlarında yer alan vejetasyon koridorları, tüm doğal ve yarı doğal habitatlar ile yakın mesafeli komşuluk ilişkisi içindedir.

Doğal ve yarı doğal habitatlar içinde büyük çoğunluğunu çalışma alanının güney doğusunda yer alan Bafa Gölü'nün oluşturduğu Durgun Tatlı Sular, en büyük ortalama yama büyüklüğü ve düşük yama sayısı ile parçalılığın en az olduğu habitat tipidir. Ayrıca peyzajdaki toplam alanı (CA: 4701.38 ha, PLAND: \%10.54), yama sayısı, yamaların birbirlerine olan mesafeleri ve yakınlık indeksi ile birlikte değerlendirildiğinde, Durgun Tatlı Sular çalışma alanında en düşük parçalanma ve en yüksek mekansal bağlantılılık ile temsil edilmektedir. Akarsular, çalışma alanının yalnızca $\% 2$ 'sine yakın bir alanı kaplamaktadır. Ancak, ortalama yama büyüklükleri, yama sayısı ve yamaların birbirlerine olan mesafeleri yakınlık indeksi ile birlikte değerlendirildiğinde, Akarsuların çalışma alanında en yüksek ikinci mekansal bağlantılılıkla temsil edildiği bulunmuştur. Peyzaj içinde doğal koridor oluşturan, doğal ve yarı doğal habitat tiplerinden bir diğeri ise Tarla Sınırları ve Yol Kenarlarında Yer Alan Vejetasyon'dan oluşmaktadır. Toplam çalışma alanının \%2.81'ini kaplayan bu habitat tipi, NP ve AREA_MN değerlerine göre parçalı bir yapı sergilese de, yamalarının komşuluk ilişkileri incelendiğinde (ENN_MN ve PROX_MN), birbirlerine yakın mesafede kümelenmiş durumda oldukları görülmektedir. Bu bakımdan peyzaj

Çizelge 2. Peyzaj metrikleri sonuçları -1

\begin{tabular}{|c|c|c|c|c|c|c|c|}
\hline Habitat Tipi & CA & PLAND & NP & AREA_MN & ENN_MN & PROX_MN & MESH \\
\hline Tuzlu Çamur ve Kum Düzlükleri & 355.12 & 0.80 & 34 & 10.44 & 203.86 & 320.63 & 0.27 \\
\hline Salicornia europaea Tuzlu Bataklıkları & 1225.67 & 2.75 & 284 & 4.32 & 41.85 & 417.64 & 2.36 \\
\hline Akdeniz Hasırotu Tuzlu Bataklıkları & 629.03 & 1.41 & 181 & 3.48 & 93.11 & 88.94 & 1.14 \\
\hline Akdeniz Tuzcul Çalılıkları & 954.82 & 2.14 & 303 & 3.15 & 155.61 & 307.88 & 0.69 \\
\hline Durgun Tatlı Sular & 4701.38 & 10.54 & 79 & 59.51 & 46.34 & 19705.15 & 376.59 \\
\hline Akarsular & 816.12 & 1.83 & 121 & 6.74 & 51.54 & 21628.13 & 7.94 \\
\hline Kızılçam Ağaçsı Matoralleri & 983.05 & 2.20 & 275 & 3.57 & 64.66 & 407.48 & 1.37 \\
\hline $\begin{array}{l}\text { Kızılçam Ağaçsı Matoralleri-Degradasyon } \\
\text { aşaması }\end{array}$ & 121.19 & 0.27 & 5 & 24.24 & 84.82 & 85.40 & 0.08 \\
\hline Arbutus andrachne Garigleri & 3686.32 & 8.27 & 645 & 5.72 & 41.31 & 1328.48 & 12.6 \\
\hline Doğu Quercus coccifera Garigleri & 2100.32 & 4.71 & 214 & 9.81 & 39.48 & 3373.48 & 9.42 \\
\hline Sarcopoterium spinosum Friganaları & 205.85 & 0.46 & 31 & 6.64 & 510.24 & 1422.22 & 0.48 \\
\hline Kızılçam Ormanları & 662.80 & 1.49 & 117 & 5.67 & 92.54 & 211.83 & 0.72 \\
\hline Doğu Akdeniz Tamarix Çalılıkları & 118.42 & 0.27 & 80 & 1.48 & 164.69 & 34.77 & 0.03 \\
\hline Tarla Tarımı & 18376.28 & 41.21 & 1267 & 14.50 & 24.42 & 2635.16 & 37.38 \\
\hline BahçeTarımı & 5924.76 & 13.29 & 1080 & 5.49 & 37.61 & 791.65 & 6.21 \\
\hline $\begin{array}{l}\text { Tarla Sınırları ve Yol Kenarlarında Yer Alan } \\
\text { Vejetasyon }\end{array}$ & 1253.10 & 2.81 & 1166 & 1.07 & 19.14 & 611.61 & 0.18 \\
\hline $\begin{array}{l}\text { Yerleşim Alanları, Endüstriyel Alanlar ve } \\
\text { Diğer Yapay Yüzeyler }\end{array}$ & 2472.29 & 5.54 & 811 & 3.05 & 27.96 & 16316.43 & 23.16 \\
\hline
\end{tabular}


içinde mekansal bağlantılılık bakımdan en yüksek altıncı habitat tipini oluşturmaktadırlar. Doğal ve yarı doğal habitatlar içinde Durgun Tatlı Sular'dan sonra hakim habitat tipleri Arbutus andrachne Garigleri ve Doğu Quercus coccifera Garigleri'nden oluşmaktadır. Her ne kadar bu habitatlar peyzaj içinde daha parçalı bir yapı ile temsil edilseler de, yamaları birbirlerine yakın mesafede, kümelenmiş biçimde ve mekansal bakımdan bağlantılı bir yapı göstermektedir. Bunun yanı sıra peyzajın yalnızca $\% 0.46$ 'sını oluşturan Sarcopoterium spinosum Friganaları nispeten daha büyük ortalama yama büyüklüğü ve ikinci en düşük yama sayısı ile mekansal bağlantılılık bakımından Doğu Quercus coccifera Garigleri ile Arbutus andrachne Garigleri arasında yer almaktadır. Bafa Gölü'nün kuzey batısında daha çok kümelenmiş şekilde yer alan Sarcopoterium spinosum Friganaları'nın en yüksek ENN_MN ve en düşük MESH değerlerine sahip olması ise, bazı yamaların çoğunluğu oluşturan diğer yamaların aksine birbirine daha uzak biçimde konumlanmış olmasından kaynaklanmaktadır. Bu sonuç Sarcopoterium spinosum Friganaları'a ait yüksek yakınlık indeksi (PROX_MN) değeri ile de desteklenmektedir.

Toplam çalışma alanının $\% 7$ 'den büyük bir bölümü ise Salicornia europaea Tuzlu Bataklıkları, Kızılçam Ağaçsı Matoralleri ve Akdeniz Tuzcul Çalııklarından oluşmaktadır. Bu habitatlar içinde Kızılçam Ağaçsı Matorallerine ait yamalar, çalışma alanının doğusunda Bafa Gölü'nün kuzeyinde yer alan yüksek kesimlerde, Doğu Quercus coccifera Garigleri arasında ve birbirlerine yakın mesafede yayılış göstermektedir. Salicornia europaea Tuzlu Bataklıkları ve Akdeniz Tuzcul Çalııkları ise, çalışma alanının doğu ve batısında deniz kıyısı ile Bafa Gölü'nün batı kıyılarına yakın alanlarda yayılış göstermektedir. Parçalı bir yapıya sahip olan bu habitatlara ait yamalar genel anlamda benzer özellik sergileseler de, Akdeniz Tuzcul Çalılıklarına ait yamaların diğer iki habitata göre nispeten daha zayıf mekansal bağlantılılığa sahip olduğu tespit edilmiştir. Mekansal bağlantıılık bakımından bu habitatları, yine deniz ve göl kıyı alanlarında yayııış gösteren Tuzlu Çamur ve Kum Düzlükleri (\%0.80) takip etmektedir.

Kızılçam Ağaçsı Matoralleri ve Doğu Quercus coccifera Garigleri ile birlikte Bafa Gölü'nün kuzeyinde yüksek kesimlerde yer alan ancak daha az parçalı bir yapıya sahip

Çizelge 3. Peyzaj metrikleri sonuçları -2

\begin{tabular}{llllllll}
\hline Habitat Tipi & CA & PLAND & NP & AREA_MN & ENN_MN & PROX_MN & MESH \\
\hline 1 & 15741.33 & 35.31 & 1008 & 15.62 & 12365.20 & 36.85 & 3684.03 \\
2 & 16557.80 & 37.14 & 960 & 17.25 & 32865.99 & 30.54 & 3818.81 \\
3 & 17809.29 & 39.94 & 1100 & 16.19 & 157070.75 & 19.43 & 7501.33 \\
\hline
\end{tabular}

1- Doğal ve Yarı Doğal Habitatların Tümü

2 - Doğal ve Yarı Doğal Habitatlar + Akarsular

3 -Doğal ve Yarı Doğal Habitatlar + Akarsular+ Tarla Sınırları ve Yol Kenarlarında Yer Alan Vejetasyon olan Kızılçam Ormanlarına (\%1.49) ait yamalar ise nispeten birbirinden daha uzak ve izole durumdadır.

Çalışma alanının yalnızca yaklaşık \%2'sini oluşturan diğer habitatlar ise peyzajda küçük ve parçalı yamalar ile düşük mekansal bağlantıııık ile temsil edilmektedir. Bunlar içinde Akdeniz Hasırotu Tuzlu Bataklıkları ve Doğu Akdeniz Tamarix Çalılıkları, çalışma alanının kuzey batısı kesiminde deniz kıyısına yakın bölgelerde yayılış gösterirken, Kızılçam Ağaçsı Matoralleri-Degradasyon aşaması Doğu Quercus coccifera Garigleri ve Kızılçam Ormanları ile karışık biçimde Bafa Gölü’nün kuzey kesiminde yer almaktadır.

Doğrusal Habitatlar ile iliş̧kili Mekansal Bağlantılılık Değerlendirmeleri

Çalışma alanında toplam 14 adet doğal ve yarı doğal habitat bulunmaktadır. Doğrusal habitatların, doğal ve yarı doğal habitatların mekansal bağlantılılığına katkısının değerlendirilmesi amacıyla öncelikle tüm bu habitatlar tek bir sınıf altında toplanarak peyzaj metrikleri yeniden hesaplanmıştır. Daha sonra öncelikle çalışma alanında en yüksek mekansal bağlantılılıkla karakterize olan Akarsular, sonra ise peyzaj içinde doğal koridor oluşturan bir diğer habitat tipi, Tarla Sınırları ve Yol Kenarlarında Yer Alan Vejetasyon koridorları, doğal ve yarı doğal habitatlara eklenerek peyzaj deseni ve mekansal bağlantılılıkta meydana gelen değişimler tespit edilmiştir. Peyzaj metriklerine ilişkin sonuç Çizelge 3 'de verilmiştir.

Doğal ve yarı doğal habitatlar çalışma alanının \%35.31'ini oluşturmaktadır. Ortalama yama büyüklüğü 15.62 ha olan 1008 yamadan oluşmaktadır. Yamalar arası mesafe $36.85 \mathrm{~m}$ iken, birlikte ele alındıklarında tek tek her bir habitatın yamalarının yakınlık indeksi ve etkin ağ büyüklüğü'nden (PROX_MN ve MESH) daha yüksek değerler ile peyzaj içinde birbirine yakın ve mekansal bağlantılılığı daha güçlü bir yapı ile karakterize olmuşlardır. Doğal ve yarı doğal habitatlara mekansal bağlantılılığı en yüksek olan Akarsular habitat sınıfı eklendiğinde, toplam alan 816.47 ha artmış, ancak yama sayısında yaklaşık \% 5 'lik bir azalma ve ortalama yama büyüklüğünde 1.63 ha artış gözlenmiştir. Ayrıca, yamalar arasındaki ortalama mesafe yaklaşık $6.5 \mathrm{~m}$ azalırken, yakınlık indeksi yaklaşık 2.5 kat artarak 32866'ya ulaşmıştır. Buna ek olarak etkin ağ büyüklüğündeki 134.78 ha'ılık artış, özellikle doğu ve batı yönünde birbirinden kopuk olarak konumlanmış olan doğal ve yarı doğal habitatların mekansal olarak bağlantılılığını sağlamakta Akarsuların önemli bir rol oynadığını göstermektedir. Bu durum özellikle deniz kıyısı 
ve Bafa Gölü kıyılarında yer alan su ve su ile ilişkili habitatların bağlantılılığının sağlanması bakımından da önemli bulunmaktadır.

Son olarak doğal ve yarı doğal habitatlar ile Akarsuların oluşturduğu sisteme, Tarla Sınırları ve Yol Kenarlarında Yer Alan Vejetasyon koridorları eklenmiştir. Bütün olarak değerlendirildiğinde, yama sayısında tekrar artışa neden olmuş ve ortalama yama büyüklüğü ise 1 ha civarında azalmıştır. Yama sayısındaki artış ile yama büyüklüğündeki azalma, Tarla Sınırları ve Yol Kenarlarında Yer Alan Vejetasyon koridorlarına ait yamaların mekansal özelliklerinden kaynaklanmaktadır. Bu noktada, doğrusal yapıdaki Tarla Sınırları ve Yol Kenarlarında Yer Alan Vejetasyon koridorlarının en yüksek ikinci yama sayısına ve en küçük ortalama yama büyüklüğüne sahip olduğu göz önünde bulundurulmalıdır.

Özellikle tarımsal alanlar içinde yoğunlaşan Tarla Sınırları ve Yol Kenarlarında Yer Alan Vejetasyon koridorları, çalışma alanını doğal bir ağ şeklinde kaplamaktadır. Tüm doğal ve yarı doğal habitatlar ile yakın mesafeli komşuluk ilişkisi içinde olan Tarla Sınırları ve Yol Kenarlarında Yer Alan Vejetasyon koridorlarının doğal ve yarı doğal habitatlar ile Akarsuların oluşturduğu sisteme eklenmesi ile birlikte, yamalar arasındaki ortalama mesafe \%36 azalırken (30.54 m’den 19.43 m'ye), yakınlık indeksi yaklaşık 5, etkin ağ büyüklüğü ise yaklaşık 2 kat artış göstermiştir. Bu sonuçlar bize, Tarla Sınırları ve Yol Kenarlarında Yer Alan Vejetasyon koridorlarının doğal ve yarı doğal habitatlar ile Akarsuların oluşturduğu sistemin mekansal bağlantılılığına çok büyük katkı sağladığını net bir şekilde göstermektedir.

\section{SONUÇ VE TARTIŞMA}

Peyzaj deseninin değerlendirilmesi yoluyla mevcut peyzajlarda her bir habitatın ekolojik açıdan öneminin belirlenmesi ve planlama / yönetim çalışmalarına altlık bilgi oluşturmak açısından büyük önem taşımaktadır (Deng ve ark., 2009; Aguilera ve ark., 2011). Bu çalışma kapsamında Büyük Menderes Deltası Milli Parkı, Bafa Gölü Tabiat Parkı ve yakın çevresinde yer alan delta sistemi örneğinde, mevcut habitatlar tanımlanmış, peyzaj deseni analiz edilmiş ve mekansal bağlantılılık bakımından doğrusal habitatların tüm delta sisteminin mekansal bağlantılılığına katkıları değerlendirilmiştir. Bu amaçla, arazi çalışmaları ve vejetasyon analizleri temelinde nesne tabanlı sınıflandırma yöntemi kullanılarak habitat haritası oluşturulmuştur. Tüm habitatların peyzaj deseni irdelendikten sonra ise, çalışma alanında geniş bir ağ oluşturan doğrusal habitatların doğal ve yarı doğal habitatların mekansal bağlantılılığa katkısı değerlendirilmiştir. Bu çalışma, Büyük Menderes Deltası Milli Parkı, Bafa Gölü Tabiat Parkı ve yakın çevresinde yer alan delta sistemi örneğinde, delta sistemlerini oluşturan doğal ve yarı doğal habitatların tanımlanması ve her bir habitatın kendine özgü karakteristikleri ile bütüncül bir sistem olarak mekansal özelliklerinin belirlenmesi açısından önem taşımaktadır. Bu çalışma peyzaj metriklerinin peyzaj deseninin analiz edilmesi ve değerlendirilmesindende önemli bir araç olduğunu ortaya koymaktadır (Andersson ve Bodin, 2009).
Peyzaj metrikleri ile çalışma alanının analizi sonucunda, beklenildiği gibi çoğunluğu verimli topraklar üzerinde yer alan delta sisteminde hakim habitatların Tarla ve Bahçe Tarımı'ndan oluştuğu tespit edilmiştir. Tarım alanları doğal ve yarı doğal habitatlar arasında bir bariyer etkisi oluşturmaktadır. Genel anlamda, habitat büyüklüğü mekansal bağlantılılığın bir göstergesi olarak tanımlanmaktadır (Leitão ve ark., 2012). Ancak, bu araştırmada doğal ve yarı doğal habitatlar arasında, hakim habitat tipleri Durgun Tatlı Sular, Arbutus andrachne Garigleri ve Doğu Quercus coccifera Garigleri olmasına rağmen, çalışma alanında en yüksek mekansal bağlantııılık Akarsu koridorları tarafından sağlanmaktadır. Diğer doğal ve yarı doğal habitatların peyzaj içindeki dağılımları ve mekansal bağlantılılıkları değişmekle birlikte, genel olarak en bağlantılı habitat tipleri sırasıyla, Durgun Tatlı Sular, Doğu Quercus coccifera Garigleri, Sarcopoterium Friganaları ve Arbutus andrachne Garigleri'nden oluşmaktadır. Doğal ve yarı doğal habitatlar birbirinden kopuk ve parçalı bir yapı sergilemektedir. Tüm çalışma alanını geniş bir ağ şeklinde saran Tarla Sınırları ve Yol Kenarlarında Yer Alan Vejetasyon koridorları ise özellikle çalışma alanının orta bölümlerinde yer alan tarım alanlarının bariyer etkisini hafifletmektedir. Bu iki habitat, diğer doğal ve yarı doğal habitatları birbirine bağlayarak çeşitli hayvan türlerine ek yaşam alanları oluşturma, peyzaj içinde hareket etme olanağı sağlama gibi pek çok potansiyel işleve sahip olmanın yanı sıra, alanın doğal değerini de yükseltmektedir.

Genel olarak, tarım alanlarındaki artış biyoçeşitliliği tehdit eden ve hatta azaltan en önemli faktörlerden birisi olarak değerlendirilmektedir (Benton ve ark., 2003; Kerbiriou ve ark., 2018). Ancak, akarsular ile tarla sınırları ve yol kenarlarında yer alan vejetasyon koridorlarının yoğun tarım alanlarındaki biyoçeşitliliği destekleme, arttırma ve koruma açısından sahip olduğu yüksek potansiyel birçok çalışmada vurgulanmıştır (Lookingbill ve ark., 2010; Bellamy ve ark., 2013; Lacoeuilhe ve ark., 2018). Bu kapsamda, iki farklı koruma statüsüne sahip olan Büyük Menderes Deltası Milli Parkı ve Bafa Gölü Tabiat Parkı arasında yer alan ve çoğunluğunu tarım alanlarının oluşturduğu Büyük Menderes delta ovasını ağ şeklinde saran akarsu ve tarla sınırları ile yol kenarlarında yer alan vejetasyon koridorları önemli bir rol üstlenmektedirler. Mekansal bağlantılılığı büyük ölçüde arttırmanın yanı sıra, akarsu ve tarla sınırları ile yol kenarlarında yer alan vejetasyon koridorları: potansiyel olarak farklı böcek/kuş/sürüngen türlerine ev sahipliği yapma, hareket olanağı sağlama, ve hayvan türlerinin peyzaj içinde artan hareket etme potansiyeli ile koruma alanları içindeki doğal ve yarı doğal habitatlarda yer alan bitki türlerinin tozlaşma / tohum taşınması vb. yollarla uzun vadeli sürdürülebilirliğine büyük katkı sağlamaktadır (Zahn ve ark., 2010). Bu kapsamda, Büyük Menderes Deltası Milli Parkı, Bafa Gölü Tabiat Parkı ve yakın çevresinde yer alan delta sistemindeki doğal ve yarı doğal habitatların sağladığı ekolojik işlevlerin ve ekosistem hizmetlerinin desteklenmesi ve sürdürülebilirliği bakımından, akarsu ve tarla sınırları ile yol kenarlarında yer alan vejetasyon 
koridorlarına ilişkin aşağıdaki önerler sunulmuştur: (1) öncelikle delta sistemindeki doğal ve yarı doğal habitatlar tanımlanmalı ve mekansal özellikleri ile birbirleriyle olan ilişkileri bakımından değerlendirilmelidir, (2) koruma alanları içinde yer alan doğal ve yarı doğal habitatlar ile birlikte bir sistem bütünü içinde değerlendirilmeli ve yönetilmelidir; (3) bu alanlarda yer alan mevcut bitki örtüsü korunmalı ve gerekli bölümlerde doğal vejetasyon örtüsünden seçilecek bitki türleri ile yeniden tesis edilmelidir; (4) tarım ve korunan alan politikalarının üretilmesinde dikkate alınmalıdırlar.

\section{KAYNAKLAR}

Aguilera F, Valenzuela LM, Botequilha-Leitão A (2011) Landscape metrics in the analysis of urban land use patterns: A case study in a Spanish metropolitan area. Landscape and Urban Planning 99 (3-4): 226238.

Andersson E, Bodin Ö (2009) Practical tool for landscape planning? An empirical investigation of network based models of habitat fragmentation. Ecography 32 (1): 123-132.

Anonim (2008) Aydın-Muğla-Denizli 1/100.000 Ölçekli Çevre Düzeni Planı Araştırma Raporu. Semra Kutluay Planlama Bürosu. A. ANKARA.

Anonim (2017) Doğa Koruma ve Milli Parklar Genel Müdürlüğü, Dilek Yarımadası. ANKARA. http://www.dilekyarimadasi.gov.tr/hakkimizda.asp?id $=1$ (Erişim Tarihi: 21/05/2019)

Atalay i (2008) Ekosistem Ekolojisi ve Coğrafyası, Cilt II, META Basım Matbaacılık Hizmetleri, İzmir. 801.

Bellamy C, Scott C, Altringham J (2013) Multiscale, presence only habitat suitability models: fine resolution maps for eight bat species. Journal of Applied Ecology 50(4): 892-901.

Benton TG, Vickery JA, Wilson JD (2003) Farmland biodiversity: is habitat heterogeneity the key? Trends in Ecology \& Evolution 18(4): 182-188.

Bilgili Y (2002). Biyolojik Çeşitlilik ve Türkiye'nin Gen Kaynakları, Mavi Yeşil 5,10-11.

Congalton RG, Green K (2008) Assessing the accuracy of remotely sensed data: principles and practices. CRC press. Florida, United States.

Deng JS, Wang K, Hong Y, Qi JG (2009) Spatio-temporal dynamics and evolution of land use change and landscape pattern in response to rapid urbanization. Landscape and Urban Planning 92 (3-4): 187-198.

Ersoy, E, Yılmaz, KT, Kesgin Atak, B, Gülçin, D (2019) Sentinel-2A Uydu Görüntüsünde Nesne Tabanlı Sınıflandırma Yöntemi Kullanılarak Kıyı Habitatlarının Haritalanması. Afyon Kocatepe Üniversitesi Fen ve Mühendislik Bilimleri Dergisi, 19(1): 152-161.
ERSOY TONYALIOĞLU E, KESGIN ATAK B

ESA (2018) https://sentinel.esa.int/documents/247904/ 685211/Sentinel-2_User_Handbook, (Erişim Tarihi: 05/06/2019)

Eşbah Tunçay H, Kelkit A, Deniz B, Kara B, Bolca, M (2009) Peyzaj sütrüktür indeksleri ile koruma alanları ve çevresindeki peyzajın geçirdiği değişimin tespiti ve alan kullanım planlaması önerilerinin geliştirilmesi: Dilek Yarımadası-Menderes Deltası Milli Parkı ve Bafa Gölü Koruma Alanı örneği. TÜBITAK, Çevre, Atmosfer, Yer ve Deniz Bilimleri Araştırma Grubu, Proje Sonuç Raporu, Ankara.

Eşbah H, Deniz B, Kara B, Kesgin B (2010) Analyzing landscape changes in the Bafa Lake Nature Park of Turkey using remote sensing and landscape structure metrics. Environmental Monitoring and Assessment 165 (1-4): 617-632.

Forman RT (1995) Some general principles of landscape and regional ecology. Landscape ecology 10 (3): 133-142.

Kerbiriou C, Azam C, Touroult J, Marmet J, Julien JF, Pellissier V (2018) Common bats are more abundant within Natura 2000 areas. Biological Conservation 217: 66-74. Lacoeuilhe A, Machon N, Julien JF, Kerbiriou C (2018) The Relative Effects of Local and Landscape Characteristics of Hedgerows on Bats. Diversity 10 (3): 72-87.

Lacoeuilhe A, Machon N, Julien JF, Kerbiriou C (2018) The relative effects of local and landscape characteristics of hedgerows on bats. Diversity, 10 (3): 1-16.

Leitão AB, Miller J, Ahern J, McGarigal K (2012) Measuring landscapes: A planner's handbook. Island press. Washington, United States.

Lookingbill TR, Elmore AJ, Engelhardt KA, Churchill JB, Gates JE, Johnson JB (2010) Influence of wetland networks on bat activity in mixed-use landscapes. Biological Conservation, 143 (4): 974-983.

Müllenhoff M, Handl M, Knipping M, Brückner H (2004) The Evolution of Lake Bafa (Western Turkey)Sedimentological, Microfaunal and Palynological Results. Coastline Reports 1: 55-66.

Redman M, Hemmami M, Kutlu ÜB, Akdamar M, Ataol M, Baldock D, Beaufoy G, Cooper T, Keenleyside C, Lise Y, Sürek M (2008) Türkiye için Doğa Dostu Tarım Kitapçığı.

Sütgibi S (2008) Doğal Ekosistemler Üzerinde İnsan Faaliyetlerinin Doğrudan ve Dolaylı Etkileri: Büyük Menderes Deltası. Marmara Coğrafya Dergisi 18: 222237.

Thompson CW (2002) Urban open space in the 21st century. Landscape and Urban Planning 60 (2): 59-72.

Zahn A, Rottenwallner A, Güttinger R (2006) Population density of the greater Mouse, eared bat (Myotis myotis), local diet composition and availability of foraging habitats. Journal of Zoology 269(4): 486-493. 
